Original Article

\title{
FACTORS CONTRIBUTING FOR NONCOMPLIANCE OF FOLLOW-UP CARE AMONG POST CARDIAC PATIENTS
}

\author{
THENMOZHI P.1* PRIYA T. ${ }^{2}$
}

${ }^{1}$ Associate Professor, Department of Medical Surgical Nursing, Saveetha College of Nursing, SIMATS, Chennai, India, ${ }^{2}$ B. Sc (N) IV Year, Saveetha College of Nursing, SIMATS, Chennai, India

Email: thenmozhi.sethu@gmail.com

Received: 13 Jul 2019, Revised and Accepted: 02 Sep 2019

\section{ABSTRACT}

Objective: Compliance in following healthy diet, physical activity schedule, cessation of smoking and alcohol, medication adherence and regular follow up is very essential component in the management of patients with cardiovascular disease to prevent reoccurrence and reduce mortality. Hence the study was conducted with the aim to assess the factors contributing for noncompliance of follow-up care among post cardiac patients.

Methods: Cross-sectional research design was employed with 50 samples who matched the inclusion criteria were selected by convenience sampling technique. Demographic variables data were collected by using structured questionnaire followed by assessed the factors contributing for noncompliance using checklist.

Results: The findings of the current study revealed that all physical, psychological, economical, social and spiritual factors were highly influenced the noncompliance. Of these, the highest percentage $80 \%$ reported lack of accessibility as well financial support and around $70 \%$ percentage reported side effects of medication and low health literacy.

Conclusion: Health care providers need to be focussed on interventional strategies especially health education in discharge plan to ensure that these patients adhere to follow up including medication adherence, following physical activity plan, dietary modification, lifestyle changes and regular follow up visit to prevent readmission and lead a successful life.

Keywords: Adherence, Cardiac patients compliance, Follow up care, Noncompliance, Side effects of medication

(C) 2019 The Authors. Published by Innovare Academic Sciences Pvt Ltd. This is an open access article under the CC BY license (http://creativecommons.org/licenses/by/4.0/) DOI: http://dx.doi.org/10.22159/ijpps.2019v11i10.34906

\section{INTRODUCTION}

Cardiovascular diseases (CVDs) are disorders of the heart and blood vessels and include coronary heart disease, cerebrovascular disease, cardiac failure, inflammatory heart disease, valvular heart diseases and other conditions. Four out of five CVD deaths are due to heart attacks and strokes. Individuals at risk of CVD may demonstrate raised blood pressure, glucose, and lipids as well as overweight and obesity. Around 17.9 million people die each year from cardiovascular diseases. It is an estimated that $31 \%$ of all deaths worldwide of these more than $75 \%$ of CVD deaths occur in low-income and middle-income countries and 85\% of all CVD deaths are due to heart attacks and strokes [1]. Approximately 1.13 billion people who have hypertension, fewer than 1 in 5 have it under control [2]. The main contributors to the rise in cardiovascular diseases are unhealthy diets, physical inactivity and the consumption of alcohol and tobacco [1]. Compliance in following a healthy diet, physical activity schedule, cessation of smoking and alcohol, medication adherence and regular follow up is very essential component in the management of patients with cardiovascular disease to prevent reoccurrence and reduce mortality.

Compliance means the following or obeying rule of order. Therapeutic compliance not only includes patient compliance with medication but also with diet, exercise, or lifestyle changes. Hence, compliance in the field of health care is often associated with individual's ability in maintaining behaviours in association with treatment plan which includes complete use of drugs, on time and making necessary changes in health [3]. It is a part of individual behaviour concordant with care instruction and suggestions [4]. Otherwise is called as noncompliance or no compliance by which the patient does not follow the instruction given by the therapist. Noncompliance lead to treatment inefficacy and increase in risk of recurrence, pain and unwanted suffering and increase of cost [5]. Noncompliance in cardiovascular patients contributes to worsening the condition and may lead to hospitalization. Optimal adherence to cardiovascular medicines confers a significant improvement in patient's outcomes [6].
Various forms of noncompliance such as medical, diet and lifestyle, etc and its prevalence in patients with heart disease has been noted and studied. Medication adherence patterns of cardiovascular diseases are reported from urban areas of different countries, but little is known from rural settings of India [7-9]. Beliefs about the causes and meaning of illness, and motivation to follow the therapy were strongly related to their compliance with healthcare [10] and patients who smoked or drank alcohol were more likely to be noncompliant [11]. Poor communication with healthcare providers was also likely to cause a negative effect on patient's compliance $[12,13]$. Non-compliant hypertension patients felt the doctors were lacking concern for their problems [14] and multiple physicians or healthcare providers prescribing medications might decrease patients' confidence in the prescribed treatment [15]. So, good communication is also very important to help patients understand their condition and therapy [16]. Forgetfulness is a widely reported factor that causes non-compliance with medication or clinic appointments [17-22]. Cost is a crucial issue in patient's compliance especially for patients with chronic disease as the treatment period could be life-long $[23,24]$. Patient's health literacy level to read understand, remember medication instructions also very important role in noncompliance [15] In another study found the determinants related to the noncompliance such as social and economic factors, condition-related, therapy-related, and patients-related factors of the multidimensional adherence model all had inconsistent evidence [25]. However, the ultimate aim of the management of cardiac patients is adherence to the follow up care to bring the desired healthy outcome by identifying the factors contributing to the nonadherence. With this significance and background the present study was conducted to explore the factors contributing to noncompliance of treatment regimen among post cardiac patients.

\section{MATERIALS AND METHODS}

Non-experimental-cross sectional research design was chosen to assess the factors contributing to the noncompliance of follow up 
care. The study was conducted after obtaining formal permission from the hospital authority with 50 samples who matched with inclusion criteria. Cardiac patients who treated either with medically or surgically or both and admitted with recurrence of cardiac disease were considered as a sample for the study and were selected by convenience sampling technique from cardiac ward and intensive care unit. Patients who were critically ill were excluded from the study. After selection of samples, the participants were explained in detail about the purpose of study and assured confidentiality. Formal informed consent was obtained for the willingness to participate in the study. The tool used for the data collection was demographic variables and checklist. Checklist consists of 20 items related to the factors contributing to the noncompliance like physical factors, psychological factors, economical factors, social Factors and spiritual factors and each item has two options such as Yes or No. This tool was prepared after reviewing the related literature and obtained experts' opinion in the cardiology, medicine and medical surgical nursing. Data was collected by interview method on one to one basis by using the checklist. Confidentiality was maintained throughout the procedure. Collected data were analysed by descriptive statistics using SPSS package.

\section{RESULTS}

The present study findings revealed that out of 50 samples, majority of them were in the age group of 51-60 y and 32(64\%) were male. Most of them $18(36 \%)$ were had no formal education, $20(40 \%)$ were unemployed and $17(34 \%)$ of their monthly income is less than Rs.5000/-Regarding the diagnosis the percentage of the cardiac, vascular and cardiovascular conditions were $12 \%$, $20 \%$ and $68 \%$ respectively and majority of them were receiving both medical and surgical treatment. More than $50 \%$ of them were taking treatment for more than one year and 46(92\%) were obtained from health information through health care professional as depicted in table 1 .

Table 1: Frequency and percentage distribution of the demographic variables among post-cardiac patients $n=50$

\begin{tabular}{|c|c|c|c|}
\hline S. No. & Demographic variable & Frequency (N) & Percentage (\%) \\
\hline \multirow[t]{5}{*}{1.} & Age in Years & & \\
\hline & A. $40-45$ & 7 & 14 \\
\hline & B. $46-50$ & 8 & 16 \\
\hline & C. $51-60$ & 23 & 46 \\
\hline & D. above 60 & 12 & 24 \\
\hline \multirow[t]{3}{*}{2.} & Gender & & \\
\hline & A. Male & 32 & 64 \\
\hline & B. Female & 18 & 36 \\
\hline \multirow[t]{5}{*}{3.} & Education & & \\
\hline & A. No formal education & 18 & 36 \\
\hline & B. Primary education & 11 & 22 \\
\hline & C. Secondary education & 10 & 20 \\
\hline & D. Any diploma or degree & 11 & 22 \\
\hline \multirow[t]{5}{*}{4.} & Occupation & & \\
\hline & A. Unemployed & 20 & 40 \\
\hline & B. Government job & 3 & 6 \\
\hline & C. Private & 14 & 28 \\
\hline & D. Cooley & 13 & 26 \\
\hline \multirow[t]{5}{*}{5.} & Monthly Income (in Rupees) & & \\
\hline & A. $<5000$ & 17 & 34 \\
\hline & B. $5000-8000$ & 11 & 22 \\
\hline & C. $8000-12000$ & 15 & 30 \\
\hline & D. $>12000$ & 7 & 14 \\
\hline \multirow[t]{4}{*}{6.} & Diagnosis & & \\
\hline & A. Cardiac condition & 6 & 12 \\
\hline & B. Vascular condition & 10 & 20 \\
\hline & C. Cardio vascular condition & 34 & 68 \\
\hline \multirow[t]{4}{*}{7.} & Method of Treatment & & \\
\hline & A. Medical treatment & 9 & 18 \\
\hline & B. Surgical treatment & 7 & 14 \\
\hline & C. Both & 34 & 68 \\
\hline \multirow[t]{4}{*}{8.} & Duration of treatment & & \\
\hline & A. Less than 6 Mo & 15 & 30 \\
\hline & B. $7 \mathrm{mo}-1 \mathrm{Y}$ & 9 & 18 \\
\hline & C. More than $1 \mathrm{Y}$ & 26 & 52 \\
\hline \multirow[t]{4}{*}{9.} & Health information obtained from & & \\
\hline & A. Health care professional & 46 & 92 \\
\hline & B. Family and friends & 1 & 2 \\
\hline & C. Mass media & 3 & 6 \\
\hline
\end{tabular}

\section{Physical factors}

Fig. 1 Shows that out of 50 samples, 35 (70\%) were non adhered to medication due to side effect of medication, $23(46 \%)$ had reported the sleep disturbance due to medication, 26(52\%) had the recurrent complaints, $17(34 \%)$ were suffered by unresolved sufferings, $15(30 \%)$ were felt the treatment complexity and $24(48 \%)$ were given drug holiday and $16(32 \%)$ of patients were influenced by white coat compliance.

\section{Psychological factors}

Table 2 depicts that out of 50 samples, 26(52\%) were felt hopelessness, $28(56 \%)$ were depressed, $13(26 \%)$ of patients were forgot to follow the instruction and had lack of empathy from prescriber, 36(72\%) had low health literacy.

\section{Economical factors}

$40(80 \%)$ were faced the problem of lack of accessibility and financial support, $15(30 \%)$ were influenced by inability to take time off work and $30(60 \%)$ were thought that health care workers acts too business like as shown in table 2 .

\section{Social factors}

$19(38 \%)$ were felt stigmatized that are not as normal as their friends and relatives and $17(34 \%)$ had poor communication with the health care provider as described in table 2 . 
Table 2: Frequency and percentage distribution of factors contributing to non-compliance of follow-up care among post cardiac patients $n=50$

\begin{tabular}{|c|c|c|c|}
\hline S. No. & Factors contributing to non-compliance & Frequency (n) & Percentage (\%) \\
\hline \multirow[t]{8}{*}{1.} & Physical Factors & & \\
\hline & 1. Side effects of medication & 35 & 70 \\
\hline & 2. Sleep disturbance due to medication & 23 & 46 \\
\hline & 3. Recurrent compliant & 26 & 52 \\
\hline & 4. Unresolved suffering & 17 & 34 \\
\hline & 5. Treatment complexity & 15 & 30 \\
\hline & 6. Drug holidays & 24 & 48 \\
\hline & 7. Whitecoat compliance & 16 & 32 \\
\hline \multirow[t]{6}{*}{2.} & Psychological Factors & & \\
\hline & 8. Hopelessness & 26 & 52 \\
\hline & 9. Depression & 28 & 56 \\
\hline & 10. Forgetfulness & 13 & 26 \\
\hline & 11. Lack of empathy from the prescriber & 13 & 26 \\
\hline & 12. Low health literacy & 36 & 72 \\
\hline \multirow[t]{5}{*}{3.} & Economical Factors & & \\
\hline & 13. Lack of accessibility & 40 & 80 \\
\hline & 14. Lack of financial support & 40 & 80 \\
\hline & 15. Inability to take time off work & 15 & 30 \\
\hline & 16. Health care workers acts too business-like & 30 & 60 \\
\hline \multirow[t]{3}{*}{4.} & Social Factors & & \\
\hline & 17. Feel stigmatized that are not as normal as their friends and relatives & 19 & 38 \\
\hline & 18. Poor communication with health care providers & 17 & 34 \\
\hline \multirow[t]{3}{*}{5.} & Spiritual Factors & & \\
\hline & 19. Disease is god's will and uncontrollable & 16 & 32 \\
\hline & 20. Supertitious belief & 14 & 28 \\
\hline
\end{tabular}

The present study findings revealed the factors contributing in noncompliance as listed in table 2 .

\section{Spiritual factors}

$16(32 \%)$ were thought that disease is god's will and uncontrollable and $14(28 \%)$ of them were influenced by superstitious belief.

\section{DISCUSSION}

Non-compliance occurs when an individual's health-seeking behavior lacks in ability and willingness to abide the prescribed therapeutic regimen by a healthcare provider. DiMatteo, 1995, estimated the compliance rate of long-term medication therapy, short-term therapy and compliance with lifestyle changes was between $40 \%$ and $50 \%, 70 \%$ and $80 \%$, and $20 \%-30 \%$ respectively [26]. Furthermore, the rates of non-compliance with different types of treatment also differ greatly by Sabate, 2003 [27]. The present also intensively analysed the factors contributing the noncompliance among 50 cardiac patients who readmitted with recurrence. The findings of the current study revealed that all physical, psychological, economical, social and spiritual factors were highly influenced the noncompliance. Of these, the highest percentage was seen in side effects of medication, lack of accessibility and financial support as well low health literacy. The present study finding was consistent with other similar study findings. Jing Jin et al. who revealed that patient-centered factors, therapy-related factors, social and economic factor, healthcare system factors, has an impact on compliance in treatment regimen [28]. According to the results of study by Abbas Heydari et al., the awareness of the disease and adherence to physical activity was low in the majority of the patients [29]. Gouranga Santra et al. reported in the study on assessment of adherence to cardiovascular medicine in rural population that overall adherence to medication for hypertension, congestive cardiac failure and ischemic heart disease was $20.83 \%, 28.7 \%$ and $32 \%$ respectively and also found that carelessness and forgetfulness was the most common cause of noncompliance of cardiovascular medicine [30]. In the current study also $26 \%$ were reported forgetfulness as on the factor of noncompliance. Similarly Atkinson $\mathrm{RC}$ et al. have shown that patients who are confronted with various obstacles, such as lack of social support, less follow their care programs [31. Likewise, Brooke Aggarwal et al. who found that $60 \%$ of patients reported sometimes forgetting to take their medication and the most common factors associated with non-compliance included forgetfulness, having other medication to take, being symptom-free [32]. Van Der Wal et al. who acknowledged after studying 954 patients suffering from congestive heart failure that depressive symptom and patients with depressive signs and low awareness face more barriers for compliance from therapeutic recommendations in congestive heart failure [33]. This findings is matched with present study fining that $28 \%$ were reported both depression and hopelessness towards the treatment. However, current study assess the cardiac patients altogether and it is not specifically analysing each conditions pertaining to cardiovascular. Furthermore treatment complexity also one of the factors for noncompliance which found in the present study and also reported by Iihara et al. [34]. On the other hand, participants may felt like health care workers acts too business-like because of repeatedly referring to several physicians, changing of drug and its dosage, and not making patient ready for self-care after discharge and these factors greatly confused them and reported as the causes of noncompliance. This factor was reported by $60 \%$ participants in the present study. Hope $\mathrm{C}$, et al. stated that patients who do not have adequate knowledge about their medication regimen were more likely to be non-adherent [5]. Jing Jin reported in review articles that several studies found that patients with higher educational level might have higher compliance [28]. This finding is contrast with the findings of Senior et al., patients with lower education level have better compliance because they might have more trust in physicians' advice [36]. Whereas in another study non-adherence was not associated with demographic, socioeconomic and clinical characteristics, satisfaction about medication information and medication concerns among Rheumatoid arthritis patients [37]. This current study is recommended to maintain therapeutic relationship, strengthen the educational programme and explore the strategies to improve therapeutic compliance. The current study is limited to assess the impact of noncompliance by measuring biochemical and biophysical parameters related to noncompliance of follow up care.

\section{CONCLUSION}

The study findings concluded that noncompliance about follow-up care still persist among cardiac patients due to various reasons. Hence, health care providers need to be focussed on interventional strategies especially health education in discharge plan to ensure that these patients adhere to follow up including medication adherence, following physical activity plan, dietary modification, lifestyle changes and regular follow up visit to prevent readmission and lead a successful life. Initiatives to be taken to strengthen the 
education programme, easy accesses to non-communicable disease clinic and reminder alert for hospital visit, frequent call for follow up at home.

\section{ACKNOWLEDGMENT}

The author would like to thank all the participants for participating in this research study and also thank the health care team members in the cardiac unit for their support to complete the study successfully.

\section{AUTHORS CONTRIBUTIONS}

All the author have contributed equally

\section{CONFLICT OF INTERESTS}

The authors declare that no conflict of interest

\section{REFERENCES}

1. https://www.who.int/cardiovascular_diseases/en/ [Last accessed on 10 Jun 2019]

2. https://www.who.int/cardiovascular_diseases/worldhypertension-day-2019/en/ [Last accessed on 10 Jun 2019]

3. Shay LE. A concept analysis: adherence and weight loss. Nurs Forum 2008;43:42-52.

4. Lehane E, McCarthy G. An examination of the intentional and unintentional aspects of medication non-adherence in patients diagnosed with hypertension. J Clin Nurs 2007;4:698-706.

5. Ulfvarson J, Bardage C. Adherence to drug treatment in association with how the patient perceives care and information on drug. J Clin Nurs 2007;2:141-8.

6. Chowdhury R, Khan H, Heydon E, Shroufi A, Fahimi S, Moore C, et al. Adherence to cardiovascular therapy: a meta-analysis of prevalence and clinical consequences. Eur Heart J 2013;34:2940-8.

7. Baroletti S, Dell'Orfano H. Medication adherence in cardiovascular disease. Circulation 2010;121:1455-8.

8. Kulkarni SP, Alexander KP, Lytle B, Heiss G, Peterson ED. Longterm adherence with cardiovascular drug regimens. Am Heart J 2006;151:185-91.

9. Bowry AD, Shrank WH, Lee JL, Stedman M, Choudhry NK. A systematic review of adherence to cardiovascular medications in resource-limited settings. J Gen Intern Med 2011;26:147991.

10. Kyngas H, Rissanen M. Support as a crucial predictor of good compliance of adolescents with a chronic disease. J Clin Nurs 2001;10:767-74.

11. Kyngas $H$, Lahdenpera $T$. Compliance of patients with hypertension and associated factors. J Ad Nurs 1999;29:832-9.

12. Apter AJ, Reisine ST, Affleck G. Adherence with twice-daily dosing of inhaled steroids. Socioeconomic and health-belief differences. Am J Respir Crit Care Med 1998;157:1810-7.

13. Bartlett EE, Grayson M, Barker R. The effects of physician communications skills on patient satisfaction; recall, and adherence. J Chronic Dis 1984;37:755-64.

14. Lim TO, Ngah BA, Rahman RA. The mentakab hypertension study project Part V-Drug compliance in hypertensive patients. Singapore Med J 1992;33:63-6.

15. Vlasnik JJ, Aliotta SL, DeLor B. Medication adherence: factors influencing compliance with prescribed medication plans. Case Manager 2005;16:47-51.

16. Lorenc L, Branthwaite A. Are older adults less compliant with prescribed medication than younger adults? Br J Clin Psychol 1993;32:485-92.
17. Cummings KM, Kirscht JP, Binder LR. Determinants of drug treatment maintenance among hypertensive persons in inner city Detroit. Public Health Rep 1982;97:99-106.

18. Kelloway JS, Wyatt RA, Adlis SA. Comparison of patients' compliance with prescribed oral and inhaled asthma medications. Arch Intern Med 1994;154:1349-52.

19. Okuno J, Yanagi $\mathrm{H}$, Tomura S. Is cognitive impairment a risk factor for poor compliance among Japanese elderly in the community? Eur J Clin Pharmacol 2001;57:589-94.

20. Hernandez Ronquillo L, Tellez Zenteno JF, Garduno Espinosa J. Factors associated with therapy noncompliance in type-2 diabetes patients. Salud Publica Mex 2003;45:191-7.

21. Ponnusankar S, Surulivelrajan M, Anandamoorthy N. Assessment of impact of medication counseling on patients' medication knowledge and compliance in an outpatient clinic in South India. Patient Educ Couns 2004;54:55-60.

22. Wai CT, Wong ML, Ng S. Utility of the health belief model in predicting compliance of screening in patients with chronic hepatitis B. Aliment Pharmacol Ther 2005;21:1255-62.

23. Ellis JJ, Erickson SR, Stevenson JG. Suboptimal statin adherence and discontinuation in primary and secondary prevention populations. J Gen Intern Med 2004;19:638-45.

24. Ponnusankar S, Surulivelrajan M, Anandamoorthy N. Assessment of impact of medication counseling on patients' medication knowledge and compliance in an outpatient clinic in South India. Patient Educ Couns 2004;54:55-60.

25. Oosterom Calo. Determinants of adherence to heart failure medication. Heart Fail Rev 2013;18:409-27.

26. DiMatteo MR. Patient adherence to pharmacotherapy: the importance of effective communication. Formulary 1995;30:596-8, 601-2, 605.

27. Sabate E. editor. Adherence to long-term therapies: evidence for action. Geneva: World Health Organization; 2003.

28. Jing Jin, Grant Edward Sklar, Vernon Min Sen Oh, Shu Chuen Li. Factors affecting therapeutic compliance: a review from the patient's perspective. Ther Clin Risk Manag 2008;4:269-86.

29. Abbas Heydari. Relationship between awareness of disease and adherence to therapeutic regimen among cardiac patients. Int ] Community Based Nurs Midwifery 2015;3:23-30.

30. Gouranga Santra. Assessment of adherence of cardiovascular medicines in rural population. Indian J Pharmacol 2015;47:600-4.

31. Atkinson RC, Branum K. Home-based disease management in congestive heart failure. Home Health Care Manag Prac 2001;13:106-13.

32. Brooke Aggarwal. Factors associated with medication adherence among heart failure patients and their caregivers. HHS Public Access 2015;5:22-7.

33. Van Der Wal MH. Unraveling the mechanisms for heart failure patients, beliefs about compliance. Heart-lung 2007;36:253-6.

34. Iihara $\mathrm{N}$, Tsukamoto $\mathrm{T}$, Morita S. Beliefs of chronically ill Japanese patients that lead to intentional non-adherence to medication. J Clin Pharm Ther 2004;29:417-24.

35. Hope $\mathrm{C}, \mathrm{Wu}$ J, Tu W, Young J, Murray M. Association of medication adherence, knowledge, and skills with emergency department visits by adults $50 \mathrm{y}$ or older with congestive heart failure. Am J Health Syst Pharm 2004;61:2043-9.

36. Senior V, Marteau TM, Weinman J. Self-reported adherence to cholesterol-lowering medication in patients with familial hypercholesterolemia: the role of illness perceptions. Cardiovasc Drugs Ther 2004;18:475-81.

37. Wee AS, MSB Mohamed Said, AB Md. Medication adherence status among rheumatoid arthritis patients. Int J Pharm Pharm Sci 2016:8:317-21. 